\title{
Experimental Development Process of a New Cement and Gypsum-Cemented Similar Material considering the Effect of Moisture
}

\author{
Qi Liu, ${ }^{1,2}$ Shaojie Chen $\mathbb{D}^{1},{ }^{1}$ Shuai Wang $\mathbb{D}^{3,4}{ }^{3}$ Jing Chai, ${ }^{2}$ and Dingding Zhang ${ }^{2}$ \\ ${ }^{1}$ Shandong University of Science and Technology, State Key Laboratory of Mining Disaster Prevention and Control Co-Founded by \\ Shandong Province and the Ministry of Science and Technology, Qingdao 266590, China \\ ${ }^{2}$ School of Energy and Mining Engineering, Xi'an University of Science and Technology, Xi'an 710054, China \\ ${ }^{3}$ China Coal Technology and Engineering Group Shenyang Research Institute, Fushun 113122, China \\ ${ }^{4}$ State Key Laboratory of Coal Safety Technology, Fushun 113122, China
}

Correspondence should be addressed to Shaojie Chen; chensj@sdust.edu.cn and Shuai Wang; wangshuai_xust@163.com

Received 21 May 2020; Revised 1 August 2020; Accepted 20 September 2020; Published 16 October 2020

Academic Editor: Zongqing Zhou

Copyright (c) 2020 Qi Liu et al. This is an open access article distributed under the Creative Commons Attribution License, which permits unrestricted use, distribution, and reproduction in any medium, provided the original work is properly cited.

\begin{abstract}
A new type of similar material considering water characteristics is developed through orthogonal experiments. The similar material is composed of river sand, barite powder, cement, gypsum, and water. We determine the best test development process. First, the proportion test scheme is designed based on the orthogonal test. Then, the effects of the moisture content, mass ratio of aggregate to binder and other components on the density, uniaxial compressive strength, elastic model, and Poisson's ratio of similar materials are analyzed by range analysis. Finally, the multiple linear regression equation between the parameters and the composition of similar materials is obtained, and the optimal composition ratio is determined according to the relationship between the test's influencing factors and the mechanical properties of similar materials. The results show that the selected raw materials and their proportioning method are feasible. The content of barite powder plays a major role in controlling the density and Poisson's ratio of similar materials. The mass ratio of aggregate to binder is the main factor that affects the uniaxial compressive strength and elastic modulus of similar materials, while the moisture content has the second largest effect on the density, uniaxial compressive strength, elastic modulus, and Poisson's ratio of similar materials. When the residual moisture content increased from 0 to $4 \%$, the uniaxial compressive strength and elastic modulus of similar materials decrease by $49.5 \%$ and $53.3 \%$, respectively, and Poisson's ratio increases by $54.8 \%$. Determining the residual moisture content that matches the design of similar material model tests is critical to improving the test accuracy and provides a reference to prepare similar materials with different requirements.
\end{abstract}

\section{Introduction}

Theoretical derivation, numerical simulation, and physical model test are three main research methods to solve complex engineering geological and geotechnical problems [1-3]. Based on the principle of similarity, the physical model can reflect the interaction relationship and mechanism of the actual geotechnical geological structure. The main characteristic of the physical model experiment is the short period, and the result is intuitive and cost-effective [4-6]. To achieve accurate physical model tests, similar materials must have similar physical and mechanical properties as the imitated objects [7-11]. Similar materials are composed of raw materials with different characteristics, and determining the proportion is an important method to simulate different real materials [12-17]. Therefore, the selection and proportion of raw materials have an important effect on the accuracy of physical model tests [18-21].

Physical model tests are widely used in underground coal mining, tunnel engineering, and other underground engineering fields [22-26]. The main factors that affect the physical and mechanical properties of similar materials are the 
selection of raw materials (aggregate, cementitious material), proportion, density, moisture content, etc. [27-33]. However, the research focus is on the selection of raw materials and their proportion, while there are few studies on the effect of the moisture content on the mechanical properties of similar materials. S. Liu and W. Liu [34] developed new similar materials that satisfy the requirements of fluid-solid coupling using river sand, calcium carbonate, talc, white cement, petroleum jelly, and antiwear hydraulic oil as raw materials; they tested the mechanical properties of the samples and applied the research results to the physical model test of water inrush from the coal floor. Li et al. [35, 36] studied the time-varying characteristics of similar material strength through block experiments and proposed the methods to reduce the time-varying characteristics of the material strength and improve the simulation results. Wen et al. [37] searched for similar materials that could simulate mudstone and explored the effect of each component of similar materials on its density, compressive strength, elastic modulus, and tensile strength. A new type of similar material with adjustable mechanical properties was proposed to satisfy the requirements of similarity with mudstone for different parameters. Zhang et al. [38] used the weakly cemented water layer as the research object and developed a weakly cemented water-resistant similar material with the uniaxial compressive strength and permeability coefficient of the material as the main indicators.

Although these similar materials have been used in geotechnical engineering and geological engineering, some problems remain [39-44]. As a coagulant, gypsum can simulate the mechanical strength of rock in a limited range, which makes the requirements of deformation or mechanical strength of similar materials difficult to satisfy. The mechanical strength of similar materials is greatly affected by moisture, and most studies focus on the selection and ratio of materials, but there are few studies on the residual moisture content of similar materials during the drying process [4550]. The effect of the combination of the ratio, density, and moisture content of similar materials on their own physical and mechanical properties is relatively rare [51-55]. In the existing research, the effect of the material composition ratio on the performance of similar materials is usually qualitatively analyzed, but there is a lack of quantitative methods to prepare similar materials under different requirements in physical model tests [56-69].

On this basis, first, raw materials of similar materials, such as river sand, barite powder, cement, and gypsum, were selected according to the preparation requirements of similar materials. Second, sample parameters such as the density, compressive strength, elastic modulus, and Poisson's ratio were tested. Third, the properties of similar materials are quantitatively analyzed by range analysis, variance analysis, and regression methods. Finally, the research results are applied to the physical model test of coal mining.

\section{Similar Materials and Methods}

2.1. Similarity Theory. Similar theory and raw materials of similar materials are the basis of the optimal proportion of ingredients. The similarity principle of the physical model test indicates that the phenomenon reproduced in the physical model should be similar to the simulated object; i.e., according to the similarity principle, the geometric dimension, load, boundary condition, gravity, strength, deformation characteristics, and water physical characteristics of the model should be similar to the simulated object. The similarity scale $C$ is the ratio of physical quantities with the same dimension between the prototype and model. According to the dimensional analysis method and basic equations of elasticity, the following similarity relations are obtained.

According to the dimensional analysis method, if the similar scale of physical quantity of the same dimension is equal and the similar scale of dimension 1 is equal to 1 , then

$$
\begin{gathered}
C_{\mu}=C_{\varepsilon}=C_{\varphi}=1, \\
C_{\sigma}=C_{\sigma_{\mathrm{c}}}=C_{\sigma_{\mathrm{t}}}=C_{E}=C_{c},
\end{gathered}
$$

where $C_{\mu}$ is the similarity ratio of Poisson's ratio, $C_{\varepsilon}$ is the strain similarity ratio, $C_{\varphi}$ is the friction angle similarity ratio, $C_{\sigma}$ is the stress similarity ratio, $C_{\sigma_{c}}$ is the compressive strength similarity ratio, $C_{\sigma_{\mathrm{t}}}$ is the tensile strength similarity ratio, $C_{E}$ is the elastic model similarity ratio, and $C_{c}$ is the cohesive force similarity ratio.

The similarity can be obtained from the equilibrium equation. The prototype equilibrium equation is

$$
\left(\sigma_{j i, j}\right)_{\mathrm{p}}+\left(f_{i}\right)_{\mathrm{p}}=0
$$

where $\left(\sigma_{j i, j}\right)_{\mathrm{p}}$ is the prototype stress tensor and $\left(f_{i}\right)_{\mathrm{p}}$ is the prototype volume force tensor.

The equilibrium equation of the model is

$$
\left(\sigma_{j i, j}\right)_{\mathrm{m}}+\left(f_{i}\right)_{\mathrm{m}}=0
$$

where $\left(\sigma_{j i, j}\right)_{\mathrm{m}}$ is the model stress tensor and $\left(f_{i}\right)_{\mathrm{m}}$ is the model volume force tensor.

According to the definition of the similarity ratio, $C_{f}=$ $\left(f_{i}\right)_{\mathrm{p}} /\left(f_{i}\right)_{\mathrm{m}}$, we substitute $C_{\sigma}, C_{L}$, and $C_{f}=C_{\gamma}$ into equation (2) to obtain

$$
\frac{C_{\sigma}}{C_{L}}\left(C_{j i, j}\right)_{\mathrm{m}}+C_{\gamma}\left(f_{i}\right)_{\mathrm{m}}=0
$$

where $C_{L}$ is the geometric similarity ratio, $C_{f}$ is the volume force similarity ratio, and $C_{\gamma}$ is the severe similarity ratio.

According to equations (3) and (4), equation (5) can be obtained:

$$
\frac{C_{L} C_{\gamma}}{C_{\sigma}}=1
$$

According to the geometric equations, physical equations, stress boundary conditions, and displacement 


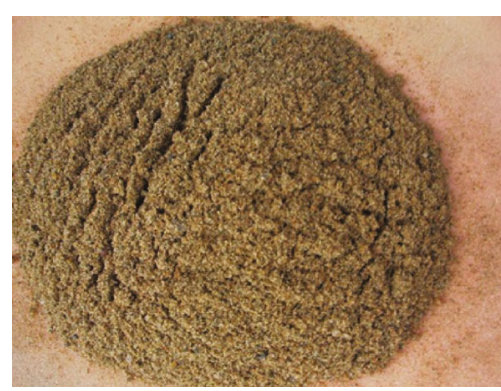

(a)

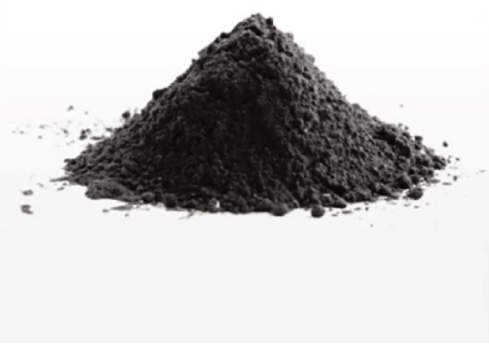

(c)

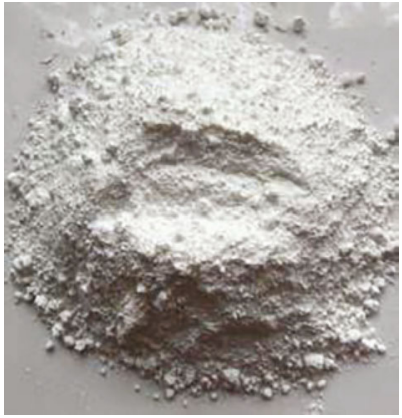

(b)

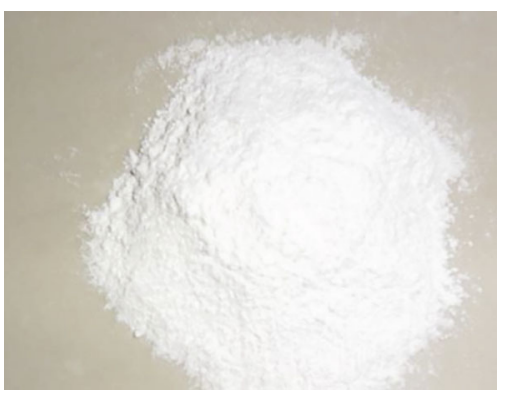

(d)

FIGURE 1: Raw materials of the similar material: (a) river sand, (b) barite powder, (c) cement, and (d) gypsum.

boundary conditions, the following relationship can be derived:

$$
\begin{gathered}
\frac{C_{\delta}}{C_{L} C_{\varepsilon}}=1, \\
\frac{C_{\sigma}}{C_{E} C_{\varepsilon}}=1,
\end{gathered}
$$

where $C_{\delta}$ is the geometric similarity ratio.

2.2. Selection of Raw Materials. River sand (China Xi'an Huizhong Construction Co., Ltd.) and barite powder (China Xi'an Jintianjiang Mining Co., Ltd.) were selected as the aggregates of similar materials. Gypsum (China Xi'an Huibang Bioengineering Co., Ltd.) and cement (China Xi'an Xinhonggao Building Decoration Materials Co., Ltd.) were selected as the binders for similar materials, as shown in Figure 1.

2.2.1. Aggregate: River Sand and Barite Powder. The average particle size of river sand is $1.0-1.5 \mathrm{~mm}$, and the average particle size of barite powder is $2.5-3.0 \mathrm{~mm}$. Gypsum and cement are used to bind river sand and barite powder into larger aggregates to increase the strength and cohesion of the material.

2.2.2. Coagulant. Cement that satisfies the P.O. 32.5 standard (National Standard for Concrete for Civil Buildings in China) is inexpensive and a good hydraulic material. It can adjust the characteristics of similar materials by improving the compressive strength, elastic modulus, and cohesion. Gypsum is semihydrated gypsum with an initial setting time of 10-15 minutes. After passing through a 300-mesh sieve, the sieve residue is less than or equal to $0.3 \%$, animal gum solution is an additive, and the solution concentration is $2.3 \%$.

2.3. Proportioning Scheme. The method is mainly composed of three parts: orthogonal test scheme of similar materials, sample manufacture, and test of the mechanical properties of the sample.

2.3.1. Orthogonal Test Scheme of Similar Materials. The orthogonal test method is based on the partial factor design method, which is used to study the proportion of similar materials. The test results are called indicators, and the parameters that may affect the test results are called factors. The specific state of each factor for comparison in experiments is called the level.

The orthogonal test design method proposed in this study can be divided into three steps:

Step 1. Determine the factors. Four factors were established: $A$-percentage of residual moisture in the total mass of similar materials, $B$-mass ratio of aggregate to cement, $C$ - mass ratio of cement to gypsum, and $D$-mass ratio of barite powder to aggregate.

Step 2. Set the level for each factor. As shown in Table 1, five levels are set for each factor.

Step 3. Design the orthogonal test design scheme in MATLAB (MATLAB 2016, MathWorks, Los Angeles, USA, 2016). The orthogonal test design scheme has 4 factors and 5 levels, which can be expressed as $L_{25}\left(5^{4}\right)$. In the orthogonal experimental design module of MATLAB software, the level of each factor is set as an input, which generates the scheme as shown in Table 2. 
TABLE 1: Orthogonal test design level.

\begin{tabular}{lcccc}
\hline Level & $A(\%)$ & $B$ & $C$ & $D(\%)$ \\
\hline 1 & 0 & $4: 1$ & $3: 7$ & 0 \\
2 & 1 & $5: 1$ & $4: 6$ & 10 \\
3 & 2 & $6: 1$ & $5: 5$ & 20 \\
4 & 3 & $7: 1$ & $6: 4$ & 30 \\
5 & 4 & $8: 1$ & $7: 3$ & 40 \\
\hline
\end{tabular}

TABLE 2: Orthogonal test schemes of similar materials.

\begin{tabular}{|c|c|c|c|c|}
\hline Test number & $A(\%)$ & $B$ & $C$ & $D(\%)$ \\
\hline 1 & 0 & $4: 1$ & $3: 7$ & 0 \\
\hline 2 & 0 & $5: 1$ & $4: 6$ & 10 \\
\hline 3 & 0 & $6: 1$ & $5: 5$ & 20 \\
\hline 4 & 0 & $7: 1$ & $6: 4$ & 30 \\
\hline 5 & 0 & $8: 1$ & $7: 3$ & 40 \\
\hline 6 & 1 & $4: 1$ & $5: 5$ & 10 \\
\hline 7 & 1 & $5: 1$ & $6: 4$ & 20 \\
\hline 8 & 1 & $6: 1$ & $7: 3$ & 30 \\
\hline 9 & 1 & $7: 1$ & $3: 7$ & 40 \\
\hline 10 & 1 & $8: 1$ & $4: 6$ & 0 \\
\hline 11 & 2 & $4: 1$ & $7: 3$ & 20 \\
\hline 12 & 2 & $5: 1$ & $3: 7$ & 30 \\
\hline 13 & 2 & $6: 1$ & $4: 6$ & 40 \\
\hline 14 & 2 & $7: 1$ & $5: 5$ & 0 \\
\hline 15 & 2 & $8: 1$ & $6: 4$ & 10 \\
\hline 16 & 3 & $4: 1$ & $4: 6$ & 30 \\
\hline 17 & 3 & $5: 1$ & $5: 5$ & 40 \\
\hline 18 & 3 & $6: 1$ & $6: 4$ & 0 \\
\hline 19 & 3 & $7: 1$ & $7: 3$ & 10 \\
\hline 20 & 3 & $8: 1$ & $3: 7$ & 20 \\
\hline 21 & 4 & $4: 1$ & $6: 4$ & 40 \\
\hline 22 & 4 & $5: 1$ & $7: 3$ & 0 \\
\hline 23 & 4 & $6: 1$ & $3: 7$ & 10 \\
\hline 24 & 4 & $7: 1$ & $4: 6$ & 20 \\
\hline 25 & 4 & $8: 1$ & $5: 5$ & 30 \\
\hline
\end{tabular}

\subsection{Preparation of the Specimen}

2.4.1. Material Preparation. Prepare raw materials according to the dosage of river sand, barite powder, cement, gypsum, and animal glue solution in Table 2.

2.4.2. Design Molds. Considering the difficulties in forming similar specimens with different moisture contents in the past, the specimen was redesigned and produced in this test. As shown in Figure 2, the size of the mold is $\Phi 50 \mathrm{~mm} \times 100$ $\mathrm{mm}$, and 3 molds are required in the test.

2.4.3. Mixing. Place the prepared raw materials in a mixing container and stir for approximately 3 minutes. After the

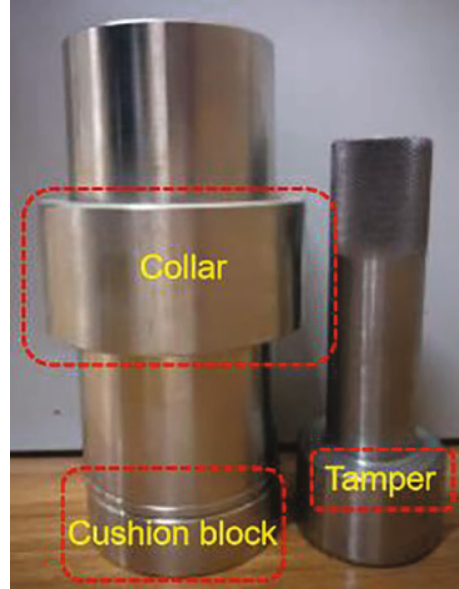

Figure 2: New test mold.

dry materials are evenly mixed, gradually add the weighed water. Simultaneously, slowly stir to avoid the difference in initial moisture content of similar materials caused by water splashing. The process is controlled within 5 minutes to prevent the material from agglomerating and affecting the strength of the test piece.

2.4.4. Filling. Put the mixed similar materials into the three molds and fill them three times. Control the filling amount of each time to approximately $40 \%$ of the mold volume and compact them. Before each filling, the surface of the last tamping is scratched to prevent delamination of the test piece. After filling, the upper surface of the test piece is troweled with a small shovel to keep the end face of the upper surface flat.

2.4.5. Demolding. Place the filled specimen mold at room temperature for 25 minutes. After molding, gently remove the mold collar, tap the outer surface of the mold with a hammer to loosen the specimen from the inner surface of the mold, and demold.

2.4.6. Grouping. Each test number in Table 2 is a group; the number of test pieces in each group is 5 . Place the test pieces in a group form, and number them in the form of $i j$, where $i$ is the test number in Table $2(i=1,2, \cdots, 24,25)$ and $j$ is the number of the test piece in the group $(j=1,2, \cdots, 5)$.

2.4.7. Maintenance. To prevent the evaporation of water, wrap the demolded specimens with a plastic wrap and place them in a light-tight sealed room. After all specimens are made, remove the plastic wrap. Place the test piece in the constant-temperature and constant-humidity box for curing, set the temperature in the box to $30^{\circ} \mathrm{C}$, take out the test piece every 30 minutes for weighing, and calculate the residual moisture content using equation (7). When the calculated residual moisture content value is close to the design value, the test can be performed.

$$
w=\frac{m_{1}-m_{0}}{m_{0}} \times 100 \%,
$$



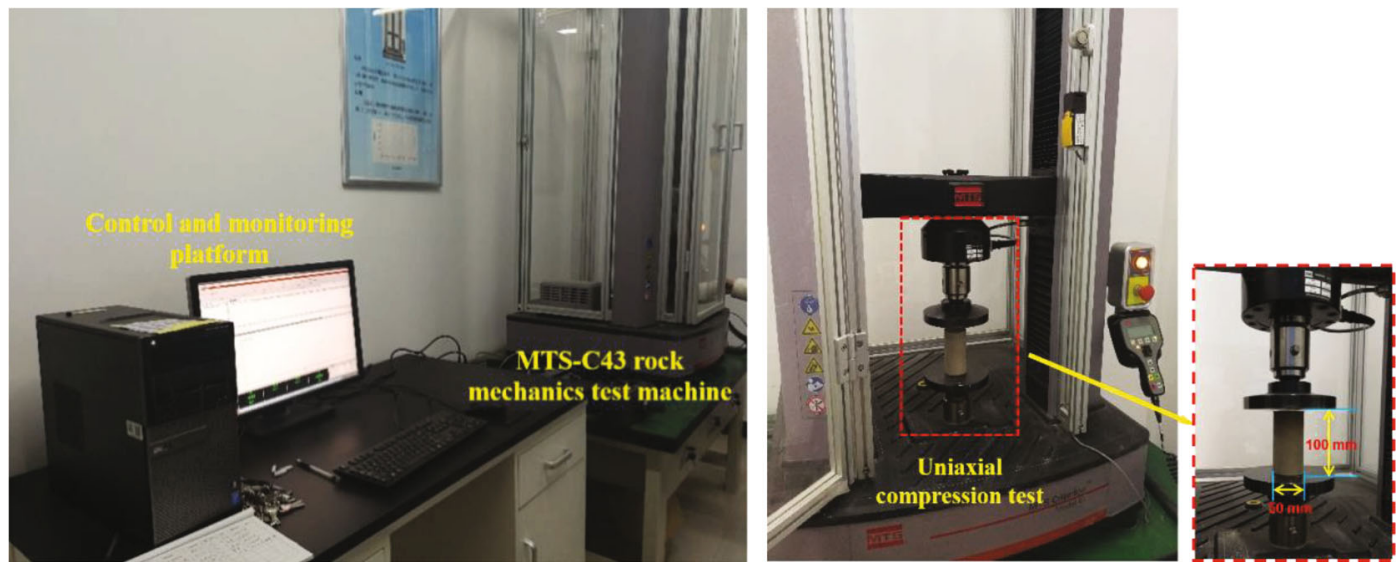

FIGURE 3: Experimental system.

where $w$ is the moisture content, $m_{1}$ is the mass of the specimen to be tested, and $m_{0}$ is the mass of the specimen when it is completely dry. Since this new similar material is made of river sand as an aggregate, if it is used in a large-scale physical simulation test, a soil moisture content measurement method can be used, such as FDR/TDR water content sensor or optical fiber moisture content sensor newly developed in recent years.

2.5. Specimen Test Index Parameters. Similar materials must satisfy the requirements of solid deformation and mechanical properties. Therefore, the index parameters of samples with the compressive strength, elastic modulus, and Poisson's ratio were tested. The MTS electronic universal testing machine (C43, MTS China Co., Ltd., Beijing, China) was used for a uniaxial compression test, using displacement control, setting preload force of $10 \mathrm{~N}$, loading rate of $1 \mathrm{~mm} / \mathrm{min}$, and sampling frequency of $2 \mathrm{~Hz}$. The test system is shown in Figure 3.

The compressive strength is tested using an MTS electronic universal testing machine, which is calculated based on the stress-strain curve and the limit load calculation. The calculation method of the uniaxial compressive strength is as follows:

$$
\sigma_{\mathrm{c}}=\frac{P}{A}
$$

where $\sigma_{\mathrm{c}}$ is the uniaxial compressive strength, $P$ is the ultimate load, and $A$ is the cross-sectional area of the sample.

The elastic modulus of the test piece is obtained by fixing the resistance strain gauge on the test sample with special glue. When the rock sample is deformed by force, the resistance strain gauge is also deformed, so its resistance will change accordingly. Under the uniaxial compression state, the slope of the straight line on the stress and longitudinal strain curve drawn by one-time loading is the elastic model modulus.

$$
E_{t}=\frac{\Delta \sigma}{\Delta \varepsilon_{l}}
$$

where $E_{t}$ is the elastic modulus, $\Delta \sigma$ is the change in longitudinal stress, and $\Delta \varepsilon_{1}$ is the change in longitudinal strain.

Poisson's ratio is calculated by taking the transverse strain value and the longitudinal strain value when the stress is $50 \%$ of the compressive strength.

$$
\mu=\frac{\Delta \varepsilon_{\mathrm{d}}}{\Delta \varepsilon_{\mathrm{l}}},
$$

where $\mu$ is Poisson's ratio, $\Delta \varepsilon_{\mathrm{d}}$ is the change in transverse strain, and $\Delta \varepsilon_{1}$ is the change in longitudinal strain.

In order to reduce the uncertainty of the test, the results of the orthogonal test are the arithmetic mean values of 5 specimens in each group, as shown in Table 3. When the moisture content changes between 0 and $4 \%$, the density distribution range of similar material specimens with different proportions is $1.733-2.003 \mathrm{~g} / \mathrm{cm}^{3}$, the compressive strength distribution range is $0.345-2.274 \mathrm{MPa}$, the elastic modulus distribution range is $68.618-518.886 \mathrm{MPa}$, Poisson's ratio distribution range is $0.016-0.184$, and the mechanical properties of similar materials widely change.

\section{Results and Discussion}

According to the measured values of sample parameters, the qualitative and quantitative relationship between the sample parameters and the proportion of similar materials was obtained. To obtain the best proportion of ingredients, a similar model test of mining engineering under certain geological conditions was used as a case for analysis, and four multivariate linear regression equations were calculated to provide the best proportion of ingredients.

We directly use statistical knowledge to analyze the test results. The range analysis method is used to analyze the effect of each factor on the mechanical parameters of similar materials under different levels. According to the orthogonal test design method in Table 1, the mechanical parameters of similar materials at the same level for each factor are averaged, and the difference between maximum and minimum values of each level is the range. The magnitude of the range reflects the effect of different factors on the mechanical 
TABLE 3: Index parameters of the specimens.

\begin{tabular}{|c|c|c|c|c|}
\hline $\begin{array}{l}\text { Test } \\
\text { number }\end{array}$ & $\begin{array}{l}\text { Density } \\
\left(\mathrm{g} / \mathrm{cm}^{3}\right)\end{array}$ & $\begin{array}{c}\text { Compressive } \\
\text { strength }(\mathrm{MPa})\end{array}$ & $\begin{array}{l}\text { Elastic modulus } \\
(\mathrm{MPa})\end{array}$ & $\begin{array}{l}\text { Poisson's } \\
\text { ratio }\end{array}$ \\
\hline 1 & 1.733 & 2.273 & 487.048 & 0.016 \\
\hline 2 & 1.864 & 2.075 & 470.081 & 0.048 \\
\hline 3 & 1.893 & 1.406 & 342.028 & 0.029 \\
\hline 4 & 1.941 & 1.565 & 371.639 & 0.104 \\
\hline 5 & 1.967 & 1.247 & 298.342 & 0.11 \\
\hline 6 & 1.898 & 2.274 & 493.638 & 0.061 \\
\hline 7 & 1.896 & 2.106 & 518.886 & 0.041 \\
\hline 8 & 1.926 & 1.459 & 379.612 & 0.122 \\
\hline 9 & 1.97 & 1.354 & 318.799 & 0.145 \\
\hline 10 & 1.826 & 0.856 & 175.253 & 0.034 \\
\hline 11 & 1.929 & 1.967 & 467.488 & 0.065 \\
\hline 12 & 1.93 & 1.762 & 373.380 & 0.156 \\
\hline 13 & 1.973 & 1.579 & 327.646 & 0.162 \\
\hline 14 & 1.823 & 1.293 & 256.631 & 0.0523 \\
\hline 15 & 1.872 & 0.726 & 188.877 & 0.07 \\
\hline 16 & 1.972 & 1.46 & 323.088 & 0.152 \\
\hline 17 & 1.983 & 1.243 & 246.563 & 0.163 \\
\hline 18 & 1.832 & 0.822 & 178.018 & 0.0729 \\
\hline 19 & 1.877 & 0.809 & 165.931 & 0.0915 \\
\hline 20 & 1.904 & 0.517 & 79.332 & 0.117 \\
\hline 21 & 2.003 & 1.502 & 340.506 & 0.184 \\
\hline 22 & 1.838 & 1.278 & 280.477 & 0.079 \\
\hline 23 & 1.877 & 0.625 & 122.776 & 0.112 \\
\hline 24 & 1.908 & 0.572 & 107.815 & 0.131 \\
\hline 25 & 1.946 & 0.345 & 68.618 & 0.173 \\
\hline
\end{tabular}

properties of similar materials. A larger range corresponds to a greater difference in test results produced by different levels of this factor, which indicates its importance, and a more obvious effect on the test results. The following is an analysis of the sensitivity of various factors using range analysis.

3.1. Results. Through range and variance analyses, the relationship between the sample index parameters (density, compressive strength, elastic modulus, and Poisson's ratio) and the four factors in the orthogonal test program was quantitatively and qualitatively analyzed. The variance analysis was performed using MATLAB (MATLAB 2016, MATLAB Information Technology Co., Ltd., Los Angeles, 2016).

3.1.1. Density Analysis. The sample density analysis is as follows: first, the qualitative analysis is studied through range analysis; in addition, the quantitative analysis is performed through analysis of variance to obtain the quantitative relationship between the sample density and the four factors.

The average value and range of the factors that affect the density of the test piece at different levels are calculated, as shown in Table 4. The range of the barite powder content is the largest and far greater than the ranges of the moisture
TABLE 4: Range analysis of the density of similar materials.

\begin{tabular}{lcccc}
\hline \multirow{2}{*}{ Level } & \multicolumn{4}{c}{ Mean density of different factors $\left(\mathrm{g} / \mathrm{cm}^{3}\right)$} \\
& $A(\%)$ & $B$ & $C$ & $D(\%)$ \\
\hline 1 & 1.8796 & 1.907 & 1.8828 & 1.8104 \\
2 & 1.9032 & 1.9022 & 1.9086 & 1.8776 \\
3 & 1.9054 & 1.9002 & 1.9086 & 1.906 \\
4 & 1.9136 & 1.9038 & 1.9088 & 1.943 \\
5 & 1.9144 & 1.903 & 1.9074 & 1.9792 \\
Range & 0.0348 & 0.0068 & 0.026 & 0.1688 \\
\hline
\end{tabular}

content, mass ratio of cement to gypsum, and mass ratio of aggregate to cement. Thus, the barite powder content has an obvious control on the density of similar materials, the moisture content and mass ratio of cement to gypsum have a certain effect, and the mass ratio of aggregate to cement has the smallest effect. The results show that the sensitivity of each factor to the density of similar materials is in the order of barite powder content, residual moisture content, mass ratio of cement to gypsum, and mass ratio of aggregate to cement. In Table $4, R_{D}>R_{A}>R_{C}>R_{B}$. Therefore, the order of factors that affect the sample density is $D>A>$ $C>B$.

Figure 4 shows a visual analysis of the effective factors that affect the density of the sample. The density of similar materials increases with the increase in the content of barite powder, residual moisture content, and mass ratio of cement to gypsum, and it slowly decreases with the increase in the ratio of mastic.

3.1.2. Compressive Strength Analysis. The compressive strength analysis method is similar to the sample density. The average and range of each level of each factor that affects the uniaxial compressive strength in the orthogonal test results are shown in Table 5. The range of the mass ratio of aggregate to cement is the largest, followed by the residual moisture content and content of barite powder, and the range of the mass ratio of cement to gypsum is the smallest. Thus, the mass ratio of aggregate to cement plays a significant role in controlling the uniaxial compressive strength of similar materials, the residual moisture content has a greater effect, the content of barite powder has a certain effect, and the mass ratio of cement to gypsum has the least effect. The sensitivity of each factor to the uniaxial compressive strength of similar materials in descending order is listed as follows: mass ratio of aggregate to cement, residual moisture content, barite powder content, and mass ratio of cement to gypsum. In Table $5, R_{B}>R_{A}>R_{D}>R_{C}$. Therefore, the order of factors that affect the sample density is $B>A>D>C$.

The sensitivity analysis curve between the uniaxial compressive strength and various factors is shown in Figure 5. The uniaxial compressive strength of similar materials decreases with the increase in the mass ratio of aggregate to cement and residual moisture content and slowly increases with the increase in the barite powder content. The mass 


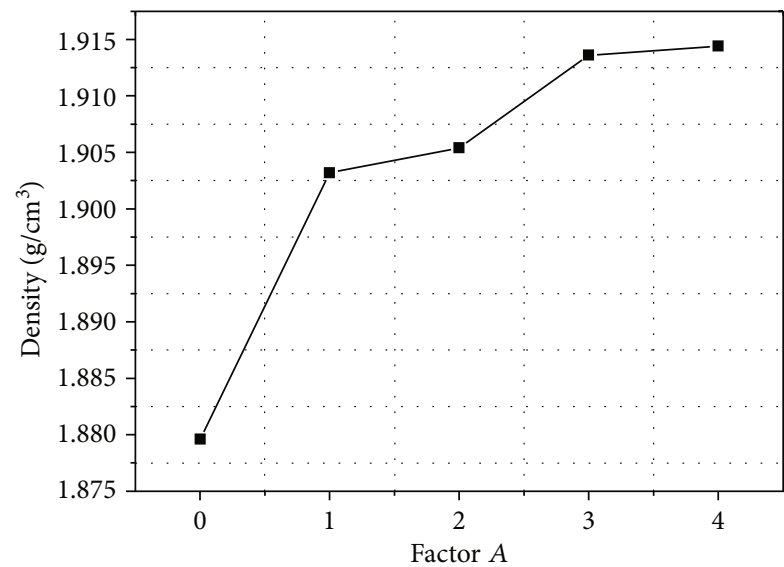

(a)

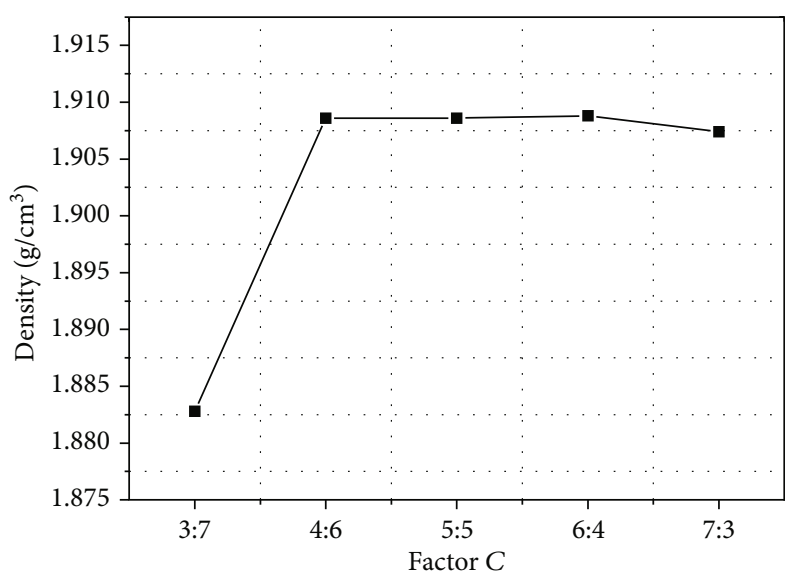

(c)

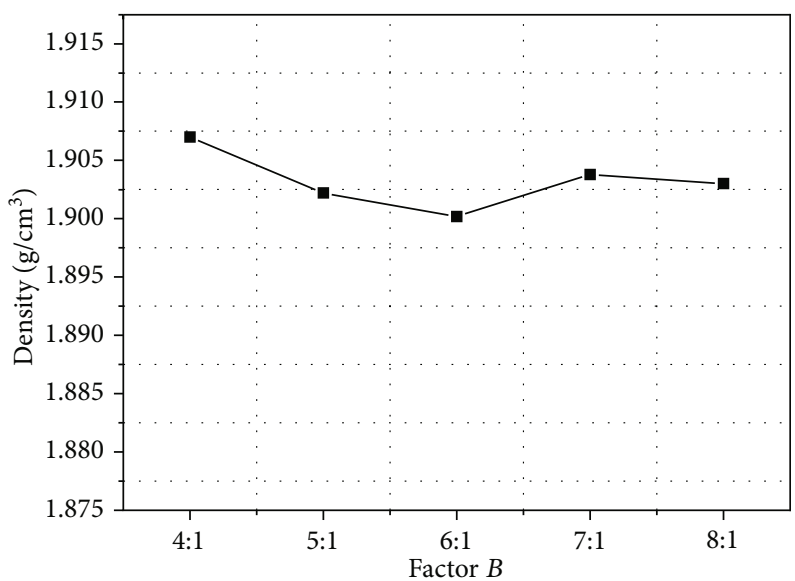

(b)

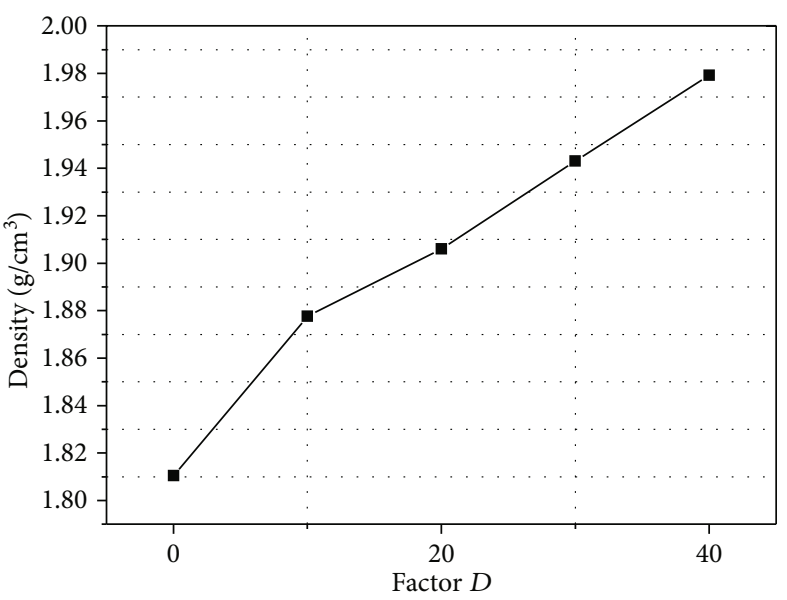

(d)

FIgURE 4: Intuitive analysis chart of density influencing factors: (a) factor $A$, (b) factor $B$, (c) factor $C$, and (d) factor $D$.

TABLE 5: Range analysis of the uniaxial compressive strength.

\begin{tabular}{lcccc}
\hline \multirow{2}{*}{ Level } & \multicolumn{5}{c}{ Average value of the uniaxial compressive strength } \\
& $A(\%)$ & $B$ & $C$ & $D(\%)$ \\
\hline 1 & 1.7132 & 1.8952 & 1.3062 & 1.3044 \\
2 & 1.6098 & 1.6928 & 1.3084 & 1.3018 \\
3 & 1.4654 & 1.1782 & 1.3122 & 1.3136 \\
4 & 0.9702 & 1.1186 & 1.3442 & 1.3182 \\
5 & 0.8644 & 0.7382 & 1.352 & 1.385 \\
Range & 0.8488 & 1.157 & 0.0458 & 0.0806 \\
\hline
\end{tabular}

ratio of cement to gypsum has little effect on the uniaxial compressive strength of similar materials.

3.1.3. Elastic Modulus Analysis. The average and range of each level of each factor that affects the elastic modulus in the orthogonal test results are shown in Table 6. The range value of the mass ratio of aggregate to cement is the largest, followed by the residual moisture content, and the range values of the barite powder content and mass ratio of cement to gypsum are smaller. Thus, the mass ratio of aggregate to cement plays an obvious role in controlling the elastic modulus of specimens of similar materials, the residual moisture content has a greater effect, and the effects of the barite powder content and mass ratio of cement to gypsum on the specimens are closer. The sensitivities of various factors to the elastic modulus of similar materials in descending order are as follows: mass ratio of aggregate to cement, moisture content, mass ratio of cement to gypsum, and barite powder content. In Table $6, R_{B}>R_{A}>R_{C}>R_{D}$. Therefore, the order of factors that affect the sample density is $B>A>C>D$.

The sensitivity analysis curve between the elastic modulus and various factors is shown in Figure 6. The elastic modulus of similar materials decreases with the increase in the mass ratio of aggregate to cement and moisture content and slowly increases with the increase in the mass ratio of cement to gypsum. The effect of the barite powder content on the elastic modulus of similar materials is not obvious. 


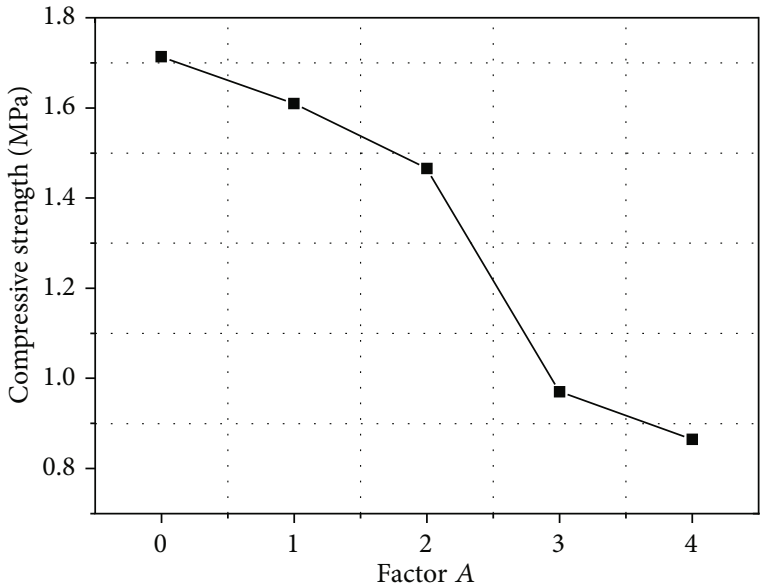

(a)

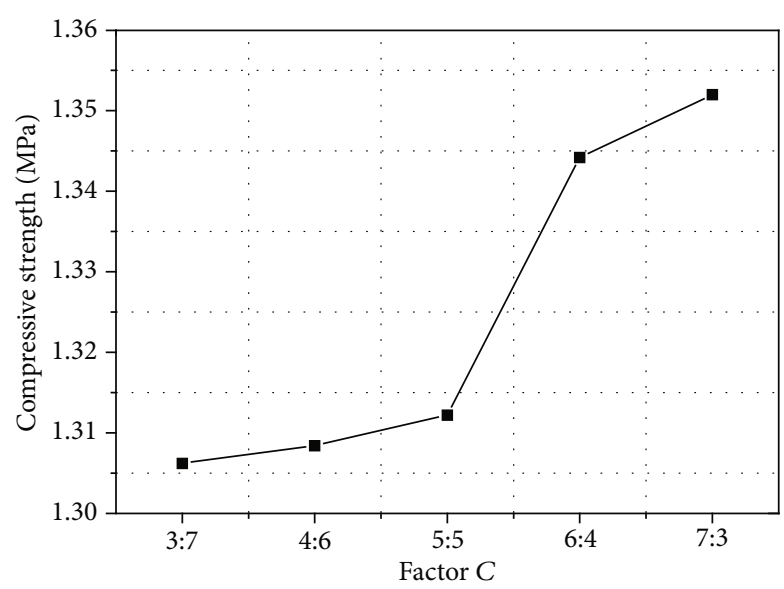

(c)

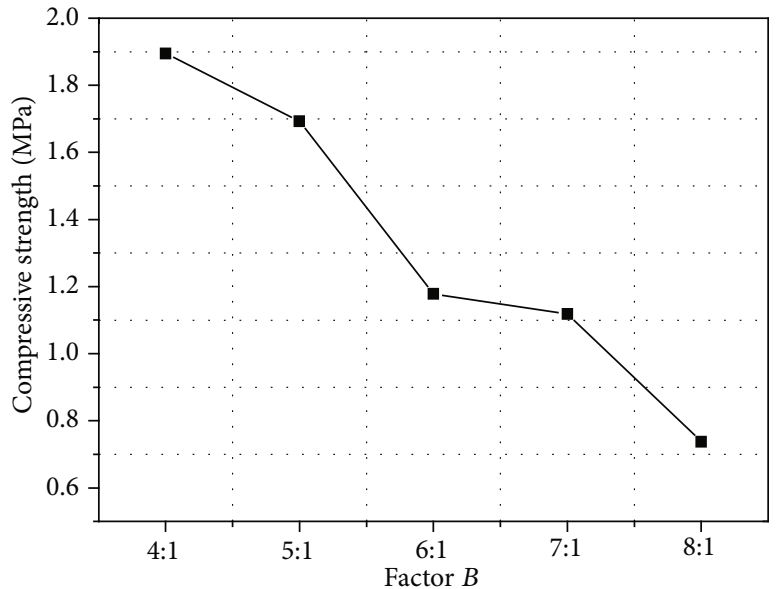

(b)

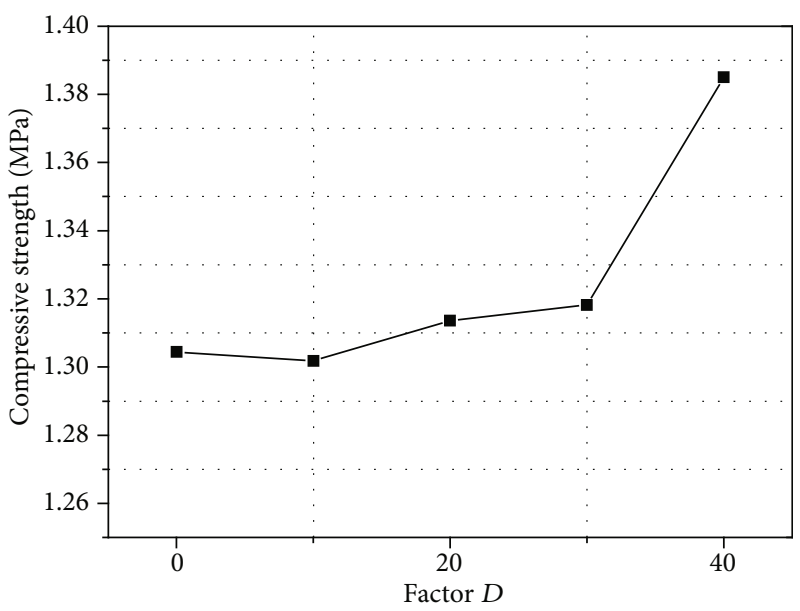

(d)

FIGURE 5: Intuitive analysis chart of compressive strength influencing factors: (a) factor $A$, (b) factor $B$, (c) factor $C$, and (d) factor $D$.

TABLE 6: Range analysis of the elastic modulus.

\begin{tabular}{lcccc}
\hline \multirow{2}{*}{ Level } & \multicolumn{5}{c}{ Mean value of the elastic modulus of different } \\
& $A(\%)$ & $B$ & $C$ & $D(\%)$ \\
\hline 1 & 393.828 & 422.354 & 276.267 & 275.486 \\
2 & 377.238 & 377.877 & 280.776 & 288.261 \\
3 & 322.804 & 270.016 & 281.496 & 303.11 \\
4 & 198.586 & 244.163 & 319.585 & 303.268 \\
5 & 184.038 & 162.084 & 318.37 & 306.372 \\
Range & 209.79 & 260.27 & 43.318 & 30.886 \\
\hline
\end{tabular}

3.1.4. Poisson's Ratio Analysis. The average and range of each level of each influencing factor of Poisson's ratio in the orthogonal test results are shown in Table 7 . The range of barite powder is the largest, followed by the moisture content and range of the mass ratio of cement to gypsum, and the range of the content of barite powder is the smallest. Thus, the content of barite powder has a significant effect on Pois- son's ratio of similar materials, the residual moisture content has a significant effect, the mass ratio of cement to gypsum has a small effect on Poisson's ratio, and the mass ratio of aggregate to cement has the least effect on Poisson's ratio. The sensitivity of each factor to Poisson's ratio of similar materials in descending order is as follows: content of barite powder, moisture content, mass ratio of cement to gypsum, and mass ratio of aggregate to cement. In Table $7, R_{D}>R_{A}$ $>R_{C}>R_{B}$. Therefore, the order of factors that affect the sample density is $D>A>C>B$.

The sensitivity analysis curve between Poisson's ratio and each factor is shown in Figure 7. Poisson's ratio of similar materials rapidly increases with the increase in the barite powder content and residual moisture content and slowly decreases with the increase in the mass ratio of cement to gypsum. The effect of the mass ratio of aggregate to cement on Poisson's ratio of similar materials is not obvious.

3.1.5. Multiple Regression Analysis. According to the results of the orthogonal test in this paper, the sensitivity analysis chart of the factors and mechanical properties of similar materials shows a good linear relationship between the 


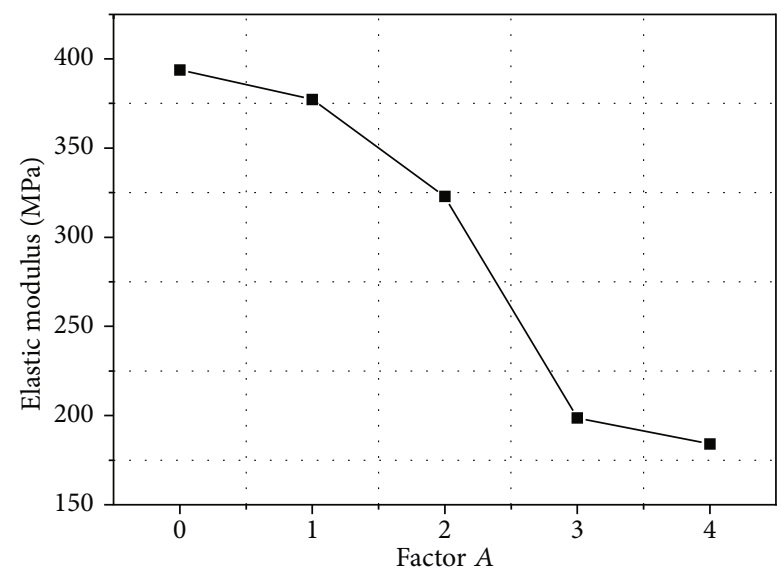

(a)

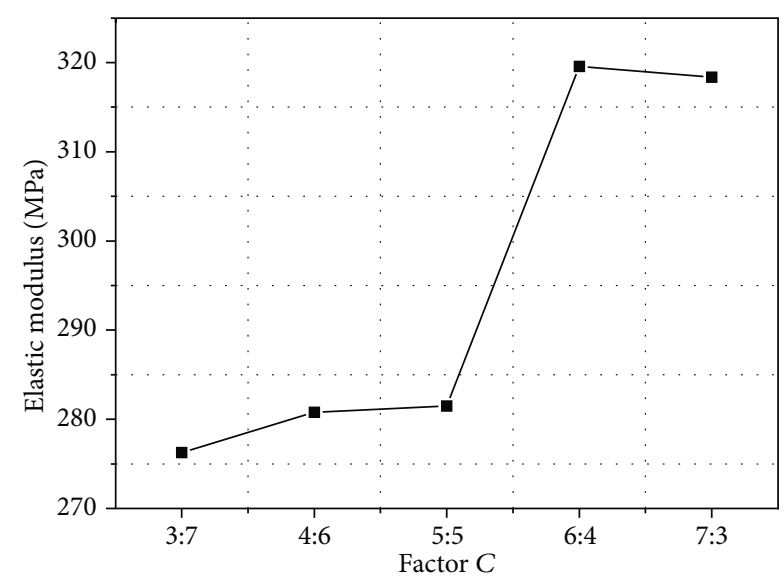

(c)

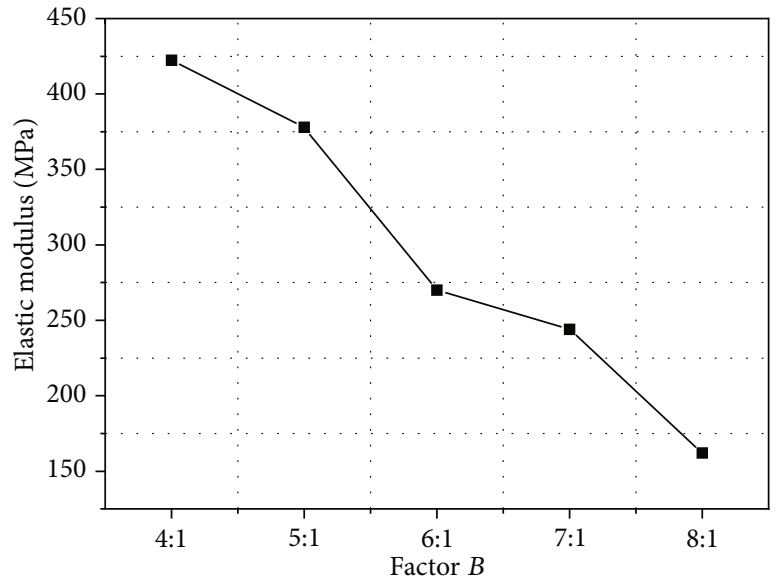

(b)

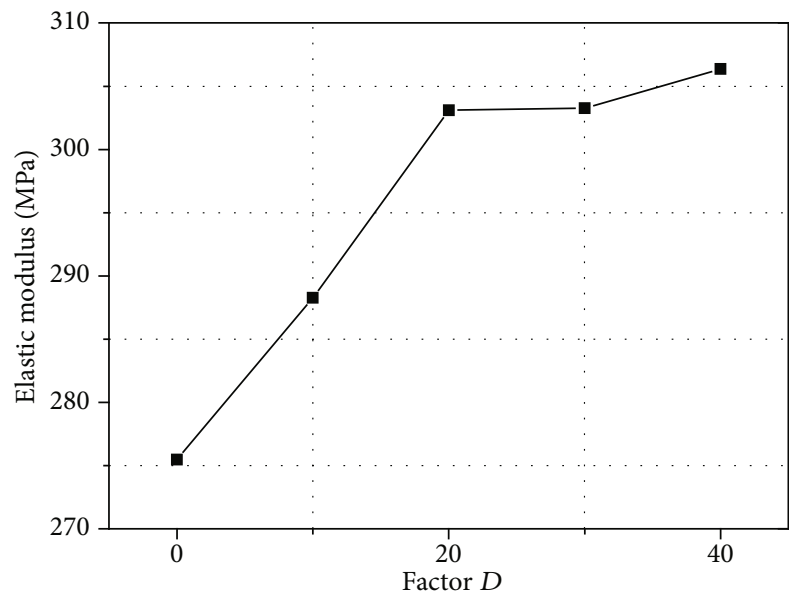

(d)

Figure 6: Intuitive analysis chart of the elastic modulus influencing factors: (a) factor $A$, (b) factor $\mathrm{B}$, (c) factor $C$, and (d) factor $D$.

TABLe 7: The range analysis of Poisson's ratio.

\begin{tabular}{lcccc}
\hline \multirow{2}{*}{ Level } & \multicolumn{4}{c}{ Mean Poisson's ratio of different factors } \\
& $A(\%)$ & $B$ & $C$ & $D(\%)$ \\
\hline 1 & 0.0614 & 0.0956 & 0.1092 & 0.05084 \\
2 & 0.0806 & 0.0974 & 0.1054 & 0.0765 \\
3 & 0.10106 & 0.09958 & 0.09566 & 0.0766 \\
4 & 0.11928 & 0.10476 & 0.09438 & 0.1414 \\
5 & 0.1358 & 0.1008 & 0.0935 & 0.1528 \\
Range & 0.0744 & 0.0052 & 0.0157 & 0.10196 \\
\hline
\end{tabular}

factors and the mechanical properties of the specimen in the orthogonal test. Thus, the multiple linear regression analysis is performed. It is defined that the content of barite powder is $X_{1}$, the mass ratio of aggregate to cement is $X_{2}$, the mass ratio of cement to gypsum is $X_{3}$, and the residual moisture content is $X_{4}$. The density of similar material specimens is $Y_{1}$, the uniaxial compressive strength is $Y_{2}$, the elastic modulus is $Y_{3}$, and Poisson's ratio is $Y_{4}$. MATLAB software is used to analyze the mechanical properties of similar materials. Regression equation (11) is obtained.

$$
\begin{aligned}
Y_{1}= & 0.004 X_{1}-0.0006 X_{2}+0.008 X_{3} \\
& +0.008 X_{4}+1.8 \\
Y_{2}= & 0.0018 X_{1}-0.289 X_{2}+0.027 X_{3} \\
& -0.23 X_{4}+3.46 \\
Y_{3}= & 0.77 X_{1}-65.43 X_{2}+25.62 X_{3} \\
& -59.82 X_{4}+761.77 \\
Y_{4}= & 0.0027 X_{1}+0.0018 X_{2}-0.008 X_{3} \\
+ & 0.0187 X_{4}+0.0071
\end{aligned}
$$

Equation (11) can be used to calculate the density, uniaxial compressive strength, elastic modulus, and Poisson's ratio of similar materials using the barite powder content, mass ratio of aggregate to cement, mass ratio of cement to gypsum, and moisture content. Generally, in the physical model test, according to the engineering geological data and similar 


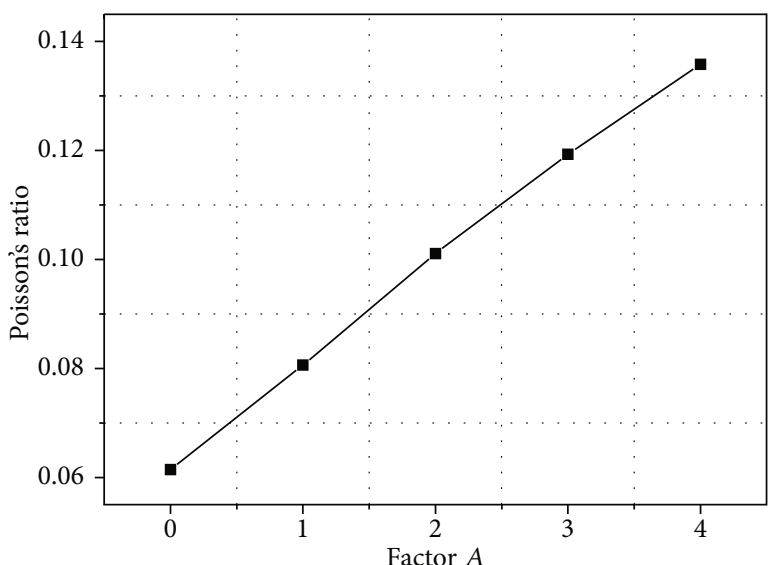

(a)

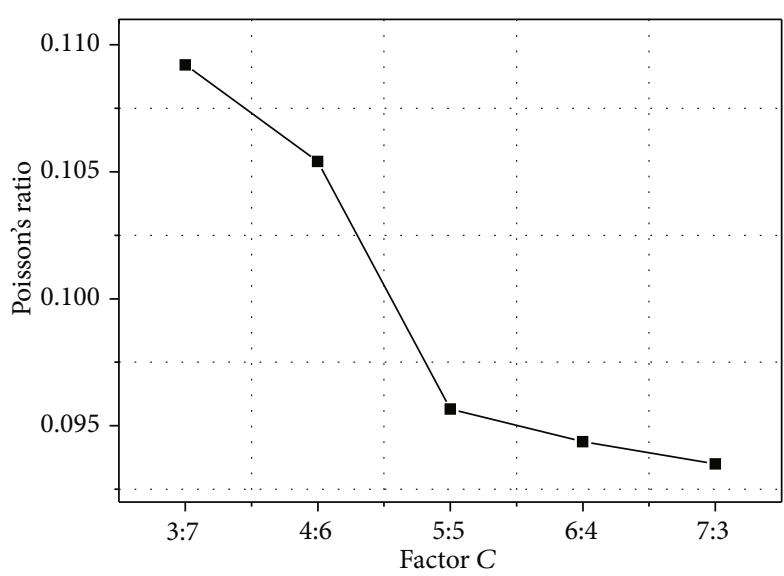

(c)

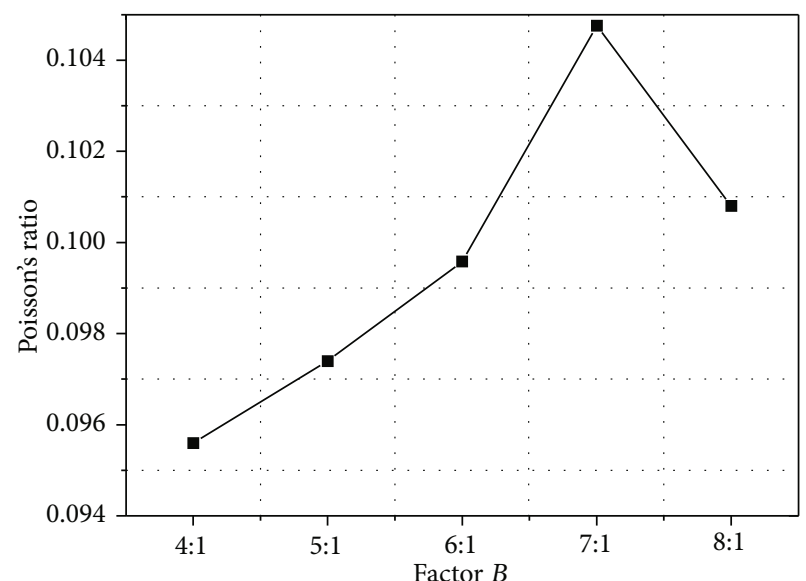

(b)

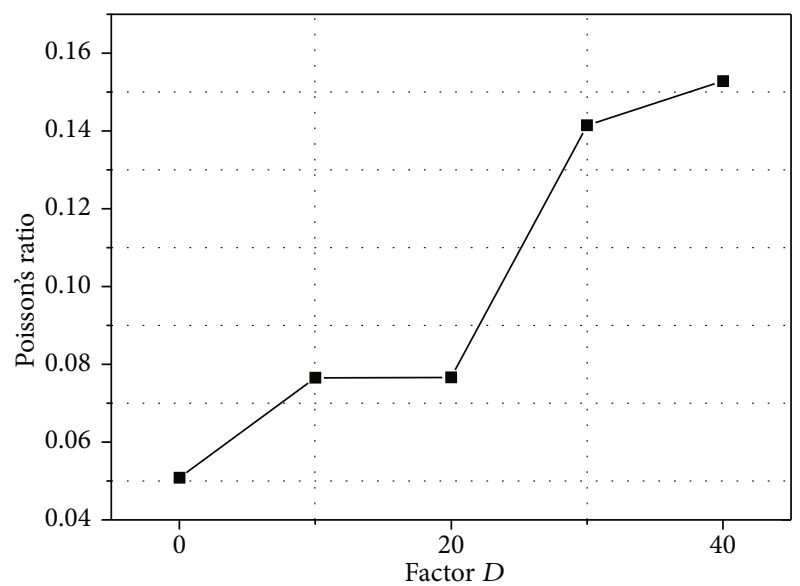

(d)

Figure 7: Intuitive analysis chart of Poisson's ratio influencing factors: (a) factor $A$, (b) factor $B$, (c) factor $C$, and (d) factor $D$.

theory, the design mechanical parameters of similar materials can be calculated. By solving equation (11), equation (12) can be obtained:

$$
\left.\begin{array}{lc}
X_{1}=152.6 Y_{1}-9.29 Y_{2}+0.06 Y_{3} & \\
X_{2}=6.997 Y_{1}-2.95 Y_{2}+0.003 Y_{3} & \\
& -13.56 Y_{4}-2.92 Y_{4}-284.66 \\
X_{3}=0.08 Y_{1}-3.69 Y_{2}+0.016 Y_{3} & -0.69 Y_{4}+1.34 \\
X_{4}=-8.46 Y_{1}+0.69 Y_{2}-0.007 Y_{3} & \\
& +20.1 Y_{4}+17.32
\end{array}\right\}
$$

When the density, uniaxial compressive strength, elastic modulus, and Poisson's ratio of similar materials are determined, the content of barite powder, mass ratio of aggregate to cement, mass ratio of cement to gypsum, and residual moisture content in similar materials can be calculated by equation (12).

3.2. Discussion. The effect of an aquifer on coal mining is a typical problem in geotechnical engineering. To explore the effect of aquifers on coal mining, a coal mine is used as an example. The Hulusu Coal Mine is located in Tuk Town, Wushen Banner, Ordos City, Inner Mongolia. It is part of the natural extension of the Dongsheng Coalfield to the southwest and belongs to the Hugilt mining area. The coalbearing stratum in this mine field is the Yanan Formation of the Middle Jurassic with 8 recoverable coal seams, of which the 2-1 coal seam and 2-2 coal seam have a burying depth of more than $600 \mathrm{~m}$. In addition, the interval between the two layers of coal is small (approximately $30 \mathrm{~m}$ ), so the mutual influence during mining is very obvious. In addition, the water content of each layer of the mine is relatively rich, and the main water damage of mining comes from the sandstone aquifer of the Yan'an Formation of the Jurassic System. To obtain the interaction mechanism between two coal seams and improve the reliability and safety of the surrounding rock support of the mine roadway, the effect of the water content on the mechanical properties of the rock must be fully considered. 
TABLE 8: Comparison between calculated and measured mechanical parameters of similar materials.

\begin{tabular}{|c|c|c|c|c|}
\hline & $\begin{array}{l}\text { Density } \\
\left(\mathrm{g} / \mathrm{cm}^{3}\right)\end{array}$ & $\begin{array}{c}\text { Compressive } \\
\text { strength }(\mathrm{MPa})\end{array}$ & $\begin{array}{c}\text { Elasticity } \\
\text { modulus }(\mathrm{MPa})\end{array}$ & $\begin{array}{l}\text { Poisson's } \\
\text { ratio }\end{array}$ \\
\hline Calculated values of mechanical parameters of similar materials & 1.73 & 0.51 & 270 & 0.2 \\
\hline Measured values of mechanical parameters of similar materials & 1.82 & 0.58 & 284 & 0.22 \\
\hline Error $(\%)$ & 5.2 & 13.7 & 5.2 & 10 \\
\hline
\end{tabular}

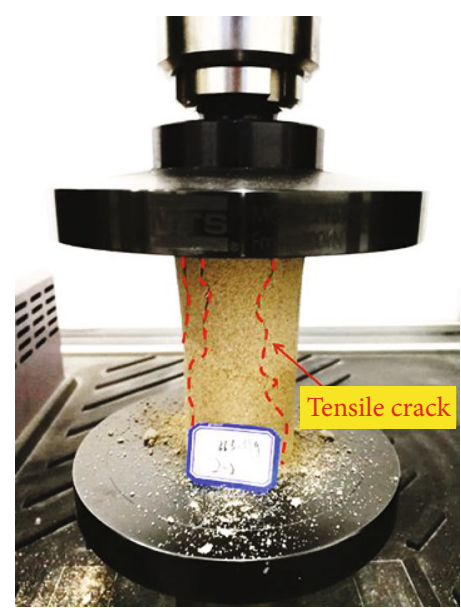

(a)

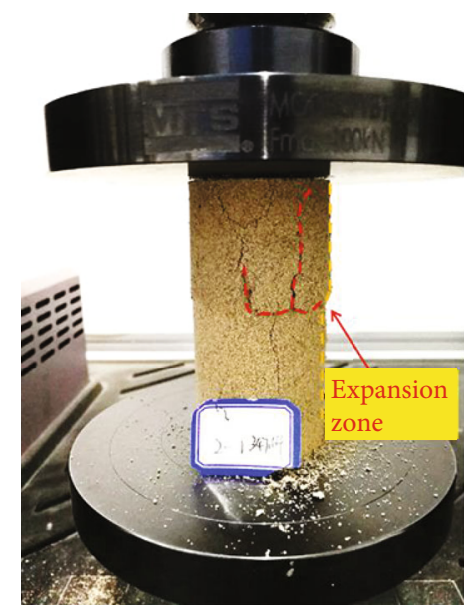

(b)

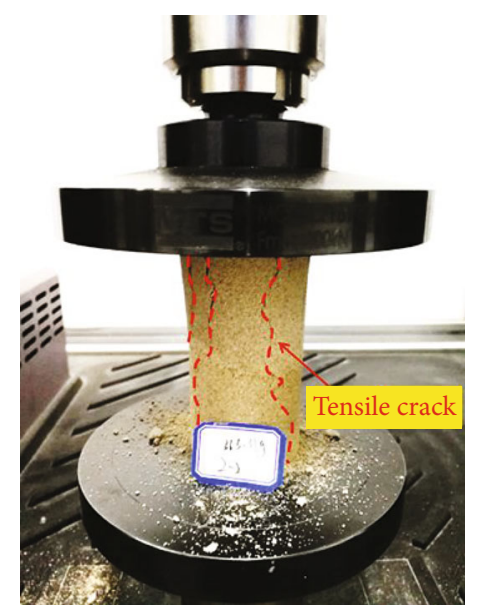

(c)

FiguRE 8: Three typical failure modes of the uniaxial compression test: (a) shear failure of the single inclined plane, (b) expansion failure, and (c) split tensile failure.

Thus, this study adopts the method of the similar material model test to study the law of spatiotemporal evolution of the stress and strain of the 2-2 coal in the mine during the 2-1 coal seam recovery process. Because the strata between the two layers of coal are thin, it is difficult to simulate the strata between two layers of coal, and higher requirements are introduced for the accuracy of the simulation test of similar materials. It is difficult to determine the suitable proportion of similar materials using the traditional experience method to effectively simulate the mechanical properties of rock strata. In this paper, the method to determine the proportion of similar materials mentioned above is introduced to solve this problem.

According to the similarity theory and prototype rock formation parameters, as shown in Table 8 , the geometric similarity ratio of the simulation test of similar materials is selected as $1: 50$, i.e., $C_{l}=50$, the similarity ratio of bulk density is $C_{\gamma}=1.56$, the similarity ratio of stress and elastic modulus is $C_{\sigma}=C_{E}=1.56 \times 50=82.5$, the similarity ratio of Poisson's ratio is $C_{v}=1$, and the experimental model parameters are calculated.

According to the physical and mechanical parameters of similar materials in Table 8 , the density is $Y_{1}=1.73 \mathrm{~g} / \mathrm{cm}^{3}$, the uniaxial compressive strength is $Y_{2}=0.51 \mathrm{MPa}$, the elastic modulus is $Y_{3}=270 \mathrm{MPa}$, and Poisson's ratio is $Y_{4}=0.2$ in equation (12). Here, $X_{1}=9, X_{2}=5.8, X_{3}=3.8$, and $X_{4}=5.2$. According to the preparation proportion of similar materials obtained by equation (12), the density, compressive strength, modulus of elasticity, and Poisson's ratio of similar materials are obtained through the uniaxial compression test.

After uniaxial compression, three typical failure modes can be achieved: shear failure of the single inclined plane (type A), expansion failure (type B), and split tensile failure (type $\mathrm{C}$ ), as shown in Figure 8. In shear failure of the single inclined plane (type A), the fracture form is a single macrofracture surface and the angle between this fracture surface and the loading direction is about $30^{\circ}$, because the shear stress on the fracture surface exceeds the limit stress. The main feature is that diagonal cracks penetrate the entire specimen, indicating that the failure mode of the specimen at this time is mainly shear fracture. In expansion failure (type B), obvious expansion occurs in the middle of the specimen during compression. The macroscopic deformation mode of the specimen shows that the failure mechanism of the specimen is mainly compression, supplemented by shear. In split tensile failure (type C), when the specimen is subjected to uniaxial compression, due to Poisson's effect, the specimen must expand along the radial direction and around. This kind of expansion trend makes a kind of interface with tensile stress in the specimen. Because the tensile strength of rock materials is relatively low, it is easy to produce tensile fractures at these tensioned interfaces, resulting in macroscopic cleavage failure modes. The internal mechanism is tensile failure.

Refer to the relevant regulations in the "Mortar Basic Performance Test Method" (Ministry of Housing and Urban- 
Rural Development of the People's Republic of China). The difference between the calculated value and the test value of the mechanical parameters of similar materials should not exceed $20 \%$ as a criterion to determine whether the fitting effect of the regression equation is accurate. In this test, the relative error between calculated and measured mechanical parameters of similar materials is $5.2-13.7 \%$, which is less than $20 \%$. Therefore, the regression equation obtained in this test can effectively calculate the proportion of similar materials in the allowable error range of the project and improve the accuracy of the similar material model test. In addition, the physical model test was performed using the optimal moisture content, and the results were consistent with the actual mining, which proves that the new similar materials are feasible in solving mining and geotechnical problems.

\section{Conclusions}

Based on the orthogonal test, a new development process of similar materials is established, where river sand and barite powder are used as the aggregate and cement and gypsum are used as the coagulant. Based on the orthogonal test, the proportion test scheme is designed. We prepare specimens to obtain parameters, such as the density, compressive strength, modulus of elasticity, and Poisson's ratio. The qualitative and quantitative relationship between the mechanical parameters of samples and the proportion of similar materials is obtained by range and variance analyses. The content of barite powder is the main factor that affects the density and Poisson's ratio of similar materials. The mass ratio of aggregate to binder is the main factor that affects the uniaxial compressive strength and elastic modulus of similar materials, while the residual moisture content is the secondary factor that affects the density, uniaxial compressive strength, modulus of elasticity, and Poisson's ratio of similar materials. The multiple linear regression equation between the mechanical parameters of the sample and the components of the similar material is obtained, and the optimum proportion of the components is further determined according to different requirements. With the similar model test of specific geological conditions as an example, according to the multiple linear regression equation, the optimal ratio of barite powder, mass ratio of aggregate to binder, mass ratio of cement to gypsum, and moisture content are determined. The simulation test of similar materials is performed. The maximum error of the test results and theoretical calculations is $13.7 \%$, which satisfies the error requirements of the similar material model test and can provide a reference for the proportion of similar materials under different requirements.

\section{Data Availability}

The data used to support the findings of this study are available from the corresponding author upon request.

\section{Conflicts of Interest}

The authors declare that they have no conflicts of interest.

\section{Acknowledgments}

This work was supported by the National Natural Science Foundation of China (Nos. 51904168 and 51804244), SDUST Research Fund (2019TDJH101), China Coal Technology and Engineering Group Co., Ltd. Science and Technology Innovation and Entrepreneurship Fund Special Project-Youth Project (2018-2-QN012), and Social Development and Industrialization Guidance Plan in Liaoning Province (2019JH8/10300099). The authors sincerely appreciate the financial supports of NSFC and the Chinese Ministry of Education. Thanks to the graduate students of Xi' an University of Science and Technology, this study would not have so smooth implementation without them.

\section{References}

[1] W. Gong, Y. Peng, M. He, and J. Wang, "Thermal image and spectral characterization of roadway failure process in geologically $45^{\circ}$ inclined rocks," Tunnelling and Underground Space Technology, vol. 49, pp. 156-173, 2015.

[2] J. Zhao, L. Yin, and W. Guo, "Stress-seepage coupling of cataclastic rock masses based on digital image technologies," Rock Mechanics and Rock Engineering, vol. 51, no. 8, pp. 2355-2372, 2018.

[3] Y. Liu, W. Li, J. He, S. Liu, L. Cai, and G. Cheng, "Application of Brillouin optical time domain reflectometry to dynamic monitoring of overburden deformation and failure caused by underground mining," International Journal of Rock Mechanics and Mining Sciences, vol. 106, pp. 133-143, 2018.

[4] Z. Luo, D. Li, B. Su, S. Zhang, and J. Deng, "On the time coupling analysis of explosion pressure and intermediate generation for multiple flammable gases," Energy, vol. 198, p. 117329, 2020.

[5] D. Song, A. Che, Z. Chen, and X. Ge, "Seismic stability of a rock slope with discontinuities under rapid water drawdown and earthquakes in large-scale shaking table tests," Engineering Geology, vol. 245, pp. 153-168, 2018.

[6] J. Yang, L. Li, and H. Lian, "Experimental evaluation of the influences of water on the fracture toughness of mudstones with bedding," Advances in Materials Science and Engineering, vol. 2019, Article ID 5693654, 2019.

[7] F. Cui, T. Zhang, X. Lai, J. Cao, and P. Shan, "Study on the evolution law of overburden breaking angle under repeated mining and the application of roof pressure relief," Energies, vol. 12, no. 23, p. 4513, 2019.

[8] C. Zang, M. Chen, G. Zhang, K. Wang, and D. Gu, "Research on the failure process and stability control technology in a deep roadway: numerical simulation and field test," Energy Science \& Engineering, vol. 8, no. 7, pp. 2297-2310, 2020.

[9] G. Zhang, L. Chen, Z. Wen et al., "Squeezing failure behavior of roof-coal masses in a gob-side entry driven under unstable overlying strata," Energy Science \& Engineering, vol. 8, no. 7, pp. 2443-2456, 2020.

[10] S. Chen, Z. Du, Z. Zhang, D. Yin, F. Feng, and J. Ma, "Effects of red mud additions on gangue-cemented paste backfill properties," Powder Technology, vol. 367, pp. 833-840, 2020.

[11] J. Yao, Y. Yin, T. Zhao, W. Ren, Y. Qiu, and W. Guo, "Segmented enlarged-diameter borehole destressing mechanism and its influence on anchorage support system," Energy Science \& Engineering, vol. 8, no. 8, pp. 2831-2840, 2020. 
[12] F. Cui, Y. Yang, X. Lai, C. Jia, and P. Shan, "Experimental study on the effect of advancing speed and stoping time on the energy release of overburden in an upward mining coal working face with a hard roof," Sustainability, vol. 12, no. 1, 2020.

[13] P. Shan and X. Lai, “An associated evaluation methodology of initial stress level of coal-rock masses in steeply inclined coal seams, Urumchi coal field, China," Engineering Computations, vol. 37, no. 6, pp. 2177-2192, 2020.

[14] Z. Chen, D. Song, C. Hu, and Y. Ke, "The September 16, 2017, Linjiabang landslide in Wanyuan County, China: preliminary investigation and emergency mitigation," Landslides, vol. 17, no. 1, pp. 191-204, 2020.

[15] S. Chen, Z. Du, Z. Zhang, H. Zhang, Z. Xia, and F. Feng, "Effects of chloride on the early mechanical properties and microstructure of gangue-cemented paste backfill," Construction and Building Materials, vol. 235, p. 117504, 2020.

[16] G. Liu, W. Cheng, L. Chen, G. Pan, and Z. Liu, "Rheological properties of fresh concrete and its application on shotcrete," Construction and Building Materials, vol. 243, article 118180, 2020.

[17] Z. Wen, E. Xing, S. Shi, and Y. Jiang, "Overlying strata structural modeling and support applicability analysis for large mining-height stopes," Journal of Loss Prevention in the Process Industries, vol. 57, pp. 94-100, 2019.

[18] Y. Fang, C. Xu, G. Cui, and B. Kenneally, "Scale model test of highway tunnel construction underlying mined-out thin coal seam," Tunnelling and Underground Space Technology, vol. 56, pp. 105-116, 2016.

[19] Q. Qu, J. Xu, R. Wu, W. Qin, and G. Hu, “Three-zone characterisation of coupled strata and gas behaviour in multi-seam mining," International Journal of Rock Mechanics and Mining Sciences, vol. 78, pp. 91-98, 2015.

[20] Q. Liu, J. Chai, S. Chen, D. Zhang, Q. Yuan, and S. Wang, "Monitoring and correction of the stress in an anchor bolt based on pulse pre-pumped Brillouin optical time domain analysis," Energy Science \& Engineering, vol. 8, no. 6, pp. 2011-2023, 2020.

[21] J. Chai, Q. Liu, J. Liu, G. Zhang, D. Zhang, and F. Qiu, “Assessing the difference in measuring bolt stress: a comparison of two optical fiber sensing techniques," Journal of Sensors, vol. 2018, Article ID 7582605, 11 pages, 2018.

[22] M. Ju, X. Li, Q. Yao, S. Liu, S. Liang, and X. Wang, "Effect of sand grain size on simulated mining-induced overburden failure in physical model tests," Engineering Geology, vol. 226, pp. 93-106, 2017.

[23] S. C. Li, Q. Wang, H. T. Wang et al., "Model test study on surrounding rock deformation and failure mechanisms of deep roadways with thick top coal," Tunnelling and Underground Space Technology, vol. 47, pp. 52-63, 2015.

[24] G. Liu, X. Guo, W. Cheng, L. Chen, and X. Cui, "Investigating the migration law of aggregates during concrete flowing in pipe," Construction and Building Materials, vol. 251, article 119065, 2020.

[25] C. Liu, S. Li, Z. Zhou et al., "Physical model tests to determine the mechanism of submarine landslides under the effect of sea waves," Natural Hazards, vol. 102, no. 3, pp. 14511474, 2020.

[26] M. Chen, S. Q. Yang, P. G. Ranjith, and Y. C. Zhang, "Cracking behavior of rock containing non-persistent joints with various joints inclinations," Theoretical and Applied Fracture Mechanics, vol. 109, p. 102701, 2020.
[27] G. Li, Y. Hu, Q. B. Li, T. Yin, J. X. Miao, and M. Yao, "Inversion method of in-situ stress and rock damage characteristics in dam site using neural network and numerical simulation-a case study," IEEE Access, vol. 8, pp. 46701-46712, 2020.

[28] Z. Xie, N. Zhang, X. Feng, D. Liang, Q. Wei, and M. Weng, "Investigation on the evolution and control of surrounding rock fracture under different supporting conditions in deep roadway during excavation period," International Journal of Rock Mechanics and Mining Sciences, vol. 123, article 104122, 2019.

[29] L. Jiang, P. Kong, P. Zhang et al., "Dynamic analysis of the rock burst potential of a longwall panel intersecting with a fault," Rock Mechanics and Rock Engineering, vol. 53, no. 4, pp. 1737-1754, 2020.

[30] S. Song, X. Liu, Y. Tan, D. Fan, Q. Ma, and H. Wang, "Study on failure modes and energy evolution of coal-rock combination under cyclic loading," Shock and Vibration, vol. 2020, Article ID 5731721, 16 pages, 2020.

[31] B. Jiang, S. Gu, L. Wang, G. Zhang, and W. Li, "Strainburst process of marble in tunnel-excavation-induced stress path considering intermediate principal stress," Journal of Central South University, vol. 26, no. 4, pp. 984-999, 2019.

[32] Y. Ding, B. Huang, K. Li, W. Du, K. Lu, and Y. Zhang, "Thermal interaction analysis of isolated hemicellulose and cellulose by kinetic parameters during biomass pyrolysis," Energy, vol. 195, p. 117010, 2020.

[33] J. Chai, Q. Liu, J. Liu, and D. Zhang, "Optical fiber sensors based on novel polyimide for humidity monitoring of building materials," Optical Fiber Technology, vol. 41, pp. 40-47, 2018.

[34] S. Liu and W. Liu, "Experimental development process of a new fluid-solid coupling similar-material based on the orthogonal test," Processes, vol. 6, no. 11, p. 211, 2018.

[35] H. Li, G. Guo, and J. Zha, "Study on time-varying characteristics of similar material model strength and the regulation measures," Environmental Earth Sciences, vol. 76, no. 15, 2017.

[36] J. Zha, H. Li, G. Guo, and J. Wang, "Influence of temperature and humidity on similar material and its control measures," Environmental Earth Sciences, vol. 76, no. 21, 2017.

[37] C. Wen, S. Jia, X. Fu, L. Meng, and Z. Zhao, "Experimental research and sensitivity analysis of mudstone similar materials based on orthogonal design," Advances in Materials Science and Engineering, vol. 2020, Article ID 2031276, 14 pages, 2020.

[38] S. Zhang, G. Fan, D. Zhang, M. Chen, and C. Zhang, "Study on material properties and similar material proportion of weakly cemented water-resisting strata," Arabian Journal of Geosciences, vol. 12, no. 11, 2019.

[39] G. C. Zhang, Z. J. Wen, S. J. Liang et al., "Ground response of a gob-side entry in a longwall panel extracting 17 m-thick coal seam: a case study," Rock Mechanics and Rock Engineering, vol. 53, no. 2, pp. 497-516, 2020.

[40] J. Zhao, X. Zhang, N. Jiang, L. Yin, and W. Guo, "Porosity zoning characteristics of fault floor under fluid-solid coupling," Bulletin of Engineering Geology and the Environment, vol. 79, no. 5, pp. 2529-2541, 2020.

[41] H. Sun, X. L. Liu, and J. B. Zhu, "Correlational fractal characterisation of stress and acoustic emission during coal and rock failure under multilevel dynamic loading," International Journal of Rock Mechanics and Mining Sciences, vol. 117, pp. 1-10, 2019.

[42] H. Li, J. Deng, X. Chen et al., “Transient temperature evolution of pulverized coal cloud deflagration in a methane-oxygen atmosphere," Powder Technology, vol. 366, pp. 294-304, 2020. 
[43] B. Li, G. Liu, W. Gao et al., "Study of combustion behaviour and kinetics modelling of Chinese Gongwusu coal gangue: model-fitting and model-free approaches," Fuel, vol. 268, 2020.

[44] C. Gao, Z. Zhou, Z. Li, L. Li, and S. Cheng, "Peridynamics simulation of surrounding rock damage characteristics during tunnel excavation," Tunnelling and Underground Space Technology, vol. 97, 2020.

[45] S. Chen, T. Jiang, H. Wang, F. Feng, D. Yin, and X. Li, "Influence of cyclic wetting-drying on the mechanical strength characteristics of coal samples: a laboratory-scale study," Energy Science \& Engineering, vol. 7, no. 6, pp. 207-213, 2019.

[46] W. Guo, F. Yu, Y. Tan, and T. Zhao, "Experimental study on the failure mechanism of layer-crack structure," Energy Science \& Engineering, vol. 7, no. 6, pp. 2351-2372, 2019.

[47] G. Wang, Y. Liu, and J. Xu, "Short-term failure mechanism triggered by hydraulic fracturing," Energy Science \& Engineering, vol. 8, no. 3, pp. 592-601, 2020.

[48] J. Guo, H. Wen, X. Zheng, Y. Liu, and X. Cheng, “A method for evaluating the spontaneous combustion of coal by monitoring various gases," Process Safety and Environmental Protection, vol. 126, no. B, pp. 223-231, 2019.

[49] Z. Wen, S. Jing, Y. Jiang et al., "Study of the fracture law of overlying strata under water based on the flow-stress-damage model," Geofluids, vol. 2019, Article ID 3161852, 12 pages, 2019.

[50] B. Cui, Y. Liu, G. Feng et al., "Experimental study on the effect of fly ash content in cemented paste backfill on its anti-sulfate erosion," International Journal of Green Energy, vol. 17, no. 12, pp. 730-741, 2020.

[51] R. Liu, Y. Yu, W. Cheng, Q. Xu, H. Yang, and J. Shen, “Comparative analyses concerning triaxial compressive yield criteria of coal with the presence of pore water," Geofluids, vol. 2020, Article ID 4670812, 15 pages, 2020.

[52] B. Chen, S. Zhang, Y. Li, Z. Li, and H. Zhou, "Physical simulation study of crack propagation and instability information discrimination of rock-like materials with faults," Arabian Journal of Geosciences, vol. 13, article 966, 2020.

[53] Z. Zhao, M. Zhang, Q. Ma, and B. Chen, "Deviation effect of coaxiality on the rock Brazilian split," Advances in Mathematical Physics, vol. 2020, Article ID 5782457, 8 pages, 2020.

[54] S. Hu, Y. Tan, H. Zhou et al., "Anisotropic modeling of layered rocks incorporating planes of weakness and volumetric stress," Energy Science \& Engineering, vol. 8, no. 3, pp. 789-803, 2020.

[55] R. Liu, W. Cheng, Y. Yu, Q. Xu, A. Jiang, and T. Lv, “An impacting factors analysis of miners' unsafe acts based on HFACS-CM and SEM," Process Safety and Environmental Protection, vol. 122, pp. 221-231, 2019.

[56] C. Wang, B. Shen, J. Chen et al., "Compression characteristics of filling gangue and simulation of mining with gangue backfilling: an experimental investigation," Geomechanics and Engineering, vol. 20, no. 6, pp. 485-495, 2020.

[57] J. Zhao, J. Chen, X. Zhang, J. Ning, and Y. Zhang, "Distribution characteristics of floor pore water pressure based on similarity simulation experiments," Bulletin of Engineering Geology and the Environment, 2020.

[58] S. Chen, T. Jiang, H. Zhang, K. Kong, and L. Bie, "Emission reduction process for dechlorinating flue-gas desulfurization gypsum and reducing wastewater effluents: application prospects from laboratory-scale studies," Energy Science \& Engineering, vol. 8, no. 8, pp. 2662-2679, 2020.
[59] Z. Qin, B. Cao, T. Li, X. Yu, and G. Chen, "Comprehensive experimental study of affecting factors on rectangular roadway stability," Advances in Civil Engineering, vol. 2020, 10 pages, 2020.

[60] D. Fan, X. Liu, Y. Tan, L. Yan, S. Song, and J. Ning, “An innovative approach for gob-side entry retaining in deep coal mines: a case study," Energy Science \& Engineering, vol. 7, no. 6, pp. 2321-2335, 2019.

[61] Z. Zhao, W. Sun, M. Zhang, X. Gao, and S. Chen, "Fracture mechanical behavior of cracked cantilever roof with large cutting height mining," Shock and Vibration, vol. 2020, Article ID 1641382, 10 pages, 2020.

[62] Q. Huang, S. Liu, W. Cheng, and G. Wang, "Fracture permeability damage and recovery behaviors with fracturing fluid treatment of coal: an experimental study," Fuel, vol. 282, p. 118809, 2020.

[63] Z. Li, H. Liu, Z. Dun, L. Ren, and J. Fang, "Grouting Effect on Rock Fracture Using Shear and Seepage Assessment," Construction \& Building Materials, vol. 242, article 118131, 2020.

[64] Q. M. Huang, S. M. Liu, G. Wang, and W. M. Cheng, "Evaluating the changes of sorption and diffusion behaviors of Illinois coal with various water-based fracturing fluid treatments," Fuel, vol. 283, article 118884, 2021.

[65] J. Chen, J. Zhao, S. Zhang, Y. Zhang, F. Yang, and M. Li, “An Experimental and Analytical Research on the Evolution of Mining Cracks in Deep Floor Rock Mass," Pure and Applied Geophysics, 2020.

[66] Z. Xia, S. Chen, X. Liu, and R. Sun, "Strength characteristics and fracture evolution of rock with different shapes inclusions based on particle flow code," Geomechanics and Engineering, vol. 22, no. 5, pp. 461-473, 2020.

[67] B. Li, J.-H. Wang, M.-S. Bi, W. Gao, and C.-M. Shu, "Experimental study of thermophysical properties of coal gangue at initial stage of spontaneous combustion," Journal of Hazardous Materials, vol. 400, article 123251, 2020.

[68] S. Fan, H. Wen, D. Zhang, Z. Yu, and X. Cheng, "Effects of crude oil on the microstructure and spontaneous combustion characteristics of coal: a case study of weakly caking coal in the Huangling No. 2 mine, China," Journal of Thermal Analysis and Calorimetry, vol. 3-4, 2020.

[69] J. Chai, Z. Ma, D. Zhang, Q. Yuan, and W. Lei, "Experimental Study on PPP-BOTDA Distributed Measurement and Analysis of Mining Overburden Key Movement Characteristics," Optical Fiber Technology, vol. 56., 2020. 